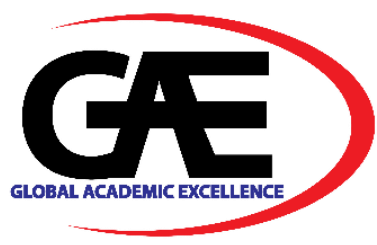

\title{
CUSTOMER SATISFACTION EVALUATION FOR ONLINE FOOD SERVICE DELIVERY SYSTEM IN MALAYSIA
}

\author{
Norshita Mat Nayan ${ }^{1 *}$, Mohd Khairul Azmi Hassan² \\ 1 Institute of IR4.0, National University of Malaysia, Malaysia \\ Email: norshitaivi@ukm.edu.my \\ 2 Kulliyyah of Information and Communication Technology, International Islamic University Malaysia, Malaysia \\ Email: mkazmi@iium.edu.my \\ Corresponding Author
}

\section{Article Info:}

\section{Article history:}

Received date: 17.10 .2020

Revised date: 06.11.2020

Accepted date: 25.11 .2020

Published date: 07.12.2020

\section{To cite this document:}

Mat Nayan, N., \& Hasan, M. K. A. (2020). Customer Satisfaction Evaluation for Online Food Service Delivery System in Malaysia. Journal of Information System and Technology Management, 5 (19), 123 136.

\section{DOI: $10.35631 / J I S T M .5190010$.}

This work is licensed under CC BY 4.0

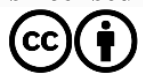

\begin{abstract}
:
The food delivery service industry is growing up and has a good potential rate in Malaysia and globally now. With social distancing the new norm, consumers are demanding to have takeout food delivered in parallel with government standard procedure in the Covid-19 pandemic. This research was conducted to examine the satisfaction of customers by using online food delivery services in Malaysia using a quantitative method. It will deal with consumer behaviour, needs, and user requirement elements in analysing their perceptions and satisfaction that will give the best-indicated system to understand consumer stability. For the accomplishment of this research, the survey was distributed to the public via online. The development of instruments based on the guideline of System Usability Scale (SUS), the reliable tools for measuring and evaluate a wide variety of products and services. Some modification in basic instruments was done to meet the requirement study. A full-fledged questionnaire was distributed among the 150 to 200 respondents to know their feedback on the food service delivery system in Malaysia. After the process of data cleaning, only 153 respondents included and considered for discussion and debate in this paper. The behaviour and user satisfaction level by using the online food services system will discuss further and some comparisons will be the main output of this research. Overall, most of the respondents satisfied with the service provided by Food Panda Service and Grab Food Service because the system easy to use and delivery time is equitable.
\end{abstract}

Keywords:

Customer Satisfaction, Online Food Ordering, Food Delivery Apps 


\section{Introduction}

The online food delivery service is gradually developing in the Malaysian market. Citizens are so active while using food ordering apps online, especially in the new norm of Covid-19 pandemic standard of procedure. Before the Covid-19 pandemic, online food delivery in Malaysia was an up-and-coming trend in urban areas with the help of technology companies such as Grab Food, Food Panda, Lala Food and etc. The service was popular among millennials, but it struggled to reach the other more mature demographics in the country. The industry, however, has now inflated with the introduction of the Movement Control Order (MCO). As a result of all these online food marketing activities, a large number of job opportunities also can be created. It also helps local vendors to connect with people who can increase their incomes.

A simplified ordering system is a website or mobile application that allows users to order food in an online platform from a food services company or a local restaurant that organises food online is similar to online shopping. As a result, online food services are becoming a large sector and will benefit Malaysia's financial climate. Online food delivery plays a significant role in customer experience and satisfaction by many factors such as availability of food, customer ratings, payment methods and human interaction (Kwong \& Shiun-Yi, 2017). To achieve maximum customer satisfaction, service providers need to focus on the quality of the service and primary goal of food delivery services. They should not have the highest level of customer satisfaction and profit only.

Research that was done by Ha \& Jang (2010); Nicolaides (2008), shows the customer satisfaction is significantly affected by the tangibility aspects of service, food quality and cost of the foods. Lee et al., (2019) prove that habit has the most influence on intentional constant intension to use, followed by expectations of performance and social impact. Besides, this reflects the importance of information quality, performance expectations, habits and social influence as factors in the continuous use of food apps by users. Besides that, bigger factor of user satisfaction also involves the effect of food quality on online loyalty, but not on e-service quality. It's also affected by discloses mediating effect role of customer satisfaction and perceived value on the relationship between both food quality and e-service quality on online loyalty toward online food delivery services.

\section{Review Of Literature}

\section{System Usability Scale (SUS)}

System Usability Scale (SUS) is a measurement tool to represent a composite measure of the usability of the system. The calculation of the SUS depends on the scores for individual items. The items score shows the contentment of respondents and its meaning on their own or not. Brooke's (1996) give attention to examining scores for the individual items of the SUS was appropriate at the time. He has developed a questionnaire with analyses based on data from 20 people. Then, the SUS has become a broadly used questionnaire for the assessment of perceived usability (Brooke, 2013; Sauro \& Lewis, 2009; Zviran, Glezer, \& Avni, 2006). With the data now available more than 20 years after its initial publication, it shows the stability of the instruments. The System Usability Scale provides a quick and dirty tool (Brooke's 1996). It is a trustable method of measuring usability in many cases. It consisted mainly of 10-items survey questions with five response options for participants which are strongly disagreed to strongly agree. 


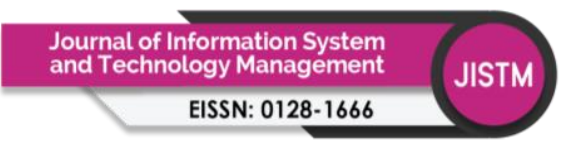

Volume 5 Issue 19 (December 2020) PP. 123-136 DOI: 10.35631/JISTM.5190010

This technique, originally developed by John Brooke in 1986, allows us to examine a broad range and variety of products and services, including hardware, software, mobile devices, websites and applications. SUS has now become an industry-standard acceptance approach, with quotes in more than 1,300 articles and publications. It shows the reliability of the standard. The System Usability Scale is a Likert Scale which includes 10 questions which users of the system can evaluate it. Respondents will rank each question from 1 to 5 based on how much they agree with the statement they are reading. Rank 5 means they completely agree, 1 means they disagree. Users will have ranked each of the 10 templates questions provided in questionnaires from 1 to 5, based on their level of agreement. For each of the odd-numbered questions, subtract 1 from the score. For each of the even-numbered questions, subtract their value from 5. Take these new values that have found and added up the total score. Next, multiply the total score by 2.5 . The result of all these tricky calculations is that the score out of 100.

\section{Customer Satisfaction For Food Delivery Services}

Online food delivery services have an important and major role in customers experience. Customers satisfaction involved many factors, such as availability of food, customer ratings, payment methods and human interaction (Kwong \& Shiun-Yi, 2017). To achieve maximum customer satisfaction, service providers need to focus on the quality of service and the definitive goal of food delivery services should be to have maximum customer satisfaction and not just only a profit (Nicolaides, 2008).

Lee et al., (2019) in his research found that, the habit has the greatest inspiration on endless use intention, followed by performance probability and social impact. Moreover, this also approves the importance of information quality, performance expectation, customer pattern and social influence as factors in inducing users' continuously have a good intention to use food delivery applications. Suhartanto et al., (2019) also agree in his research the uninterrupted effect of food quality on online is customer loyalty, but not online service quality. Besides that, it also discloses the fractional negotiation role of customer satisfaction and perceived value on the relationship between both food quality and online service quality very important for online food services delivery system.

\section{Consumer Convenience In Food Delivery Services}

Food Delivery Services System must-have features of customer convenience. It's important to promote their business and services provided to customers by promoting their offering, especially on their request making it convenient for the consumers to order from them. Service quality on user convenience should be given a considerable preference (Chen et al., 2011). Yeo et al., (2017) detected that only a few studies explain the issues of customer experience with online food delivery services and variables such as convenience, hedonism encouragement, time-saving alignment, online purchase intention experience, consumer behaviour and behavioural intention to influence customers while pursuing online food delivery service applications. Research that was done by Jayadevan et al., (2019) mentions the issue and discovered that digital applications have emerged as one of the fastest-growing developments in food delivery as consumers today have the privilege to choose from a variety of cuisines at anywhere, anytime from a range of food providers listed in the e-commerce space. Some indicators as added attractions like no minimum order value and the multitude of payment options like net banking, digital wallets and cash on delivery all have increased the consumer convenience. Eight main gratifications behind the use of food delivery service like 


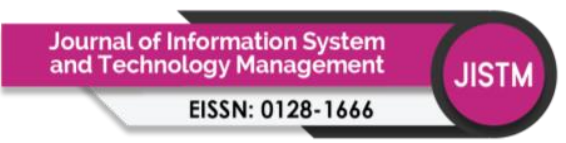

Volume 5 Issue 19 (December 2020) PP. 123-136 DOI: 10.35631/JISTM.5190010

convenience, societal pressure, customer experience, delivery experience, the search of restaurants, quality control, listing and ease-of-use were determined by Ray et al., (2019). In addition, the consumer experience, the search of restaurants, ease of use and the listing of decent food were a significant precursor of the intention to use the food delivery service system.

\section{Technology and Food Delivery Services System}

Technology plays a major role in smartphone food delivery services. Applications can be downloaded within a few seconds and order and purchasing process takes only a few minutes (Gupta, 2019; Ghadiyali, 2017). Technology is actively creating new dining experiences and it is important to transform the way customers choose to enjoy a meal. Because of technology, there seems to be an expanding capability in the food supply industry and there are great opportunities and threats within the industry although most competitors have come to light. Food service providers should start changing their offerings to address the latest dynamics as consumers change over generations (Kwong \& Shiun-Yi, 2017). The expectations of the customer continue to follow the latest trends, so it is recommended that the organisation needs to progress and keep on developing the customers' expectations (Van \& Berner, 2003). Vinaik et al., (2019) also pointed out that food apps have started to emerge as a pattern as they suit with many restaurants and understand the connection between restaurants and consumers.

Many other variables are resulting in higher sales, such as convenience accessibility of use, easy payment methods, variety of food and restaurants, delivery schedule and time, customer service, etc. They also described that now the majority of participants are aware and have a knowledge of using these apps and make use of the advantages and make purchases continuously. Smartphone apps are innovative channels for delivering individual health behaviour changes and in building healthy eating habits by including nutritional facts about menu items said Okumus \& Bilgihan, (2014). Jacob et al., (2019) argued that these food apps now act as the only window for ordering from a variety of restaurants, as this has also started to change the client's thinking. The online food ordering system will set up an online food menu with the support of smart mobile applications and deliver the expected food items to the user's doorway. It frees customers from visiting the restaurants and from waiting for a long time in the restaurants. Lee et al., (2017) discussed on consumer experience in buying food delivery via mobile apps and found that user-generated information, company-generated information and system quality had a significant impact on perceived usefulness. In part due, system quality and design quality significantly influence usefulness and ease of use that improved perceived usefulness and in spin, perceived usefulness and perceived ease of use influenced attitudes towards mobile app use.

\section{Research Methodology}

The following sections discuss the method, evaluation measures, participants and result of the study. The main objectives of this study to evaluate the food service delivery system in Malaysia. The instrument is an adaptation from the knowledge of the SUS method and technique. Some correlated modification was done to make it suitable and more significant with respondents. The selection of respondents using the snowball method, whereby the sampling is where research participants recruit other participants for a test or study. It's called snowball sampling because the approach is like a rolling ball, it picks up more things along the way and becomes larger and larger. Snowball sampling is a non-probability sampling method. It doesn't have the probability involved and simple random sampling for any particular 
participant being chosen. As researchers, we used our judgment to choose participants. Snowball sampling consists of two steps:

1. Identify potential respondents of subjects in the population.

2. The main subjects of the population will recruit another layer of respondents. They can ask those subjects to recruit other people and then ask those people to recruit others. Participants should be made aware that they do not have to provide any other names.

Approximately 150 to 200 respondents participated in this research. The questionnaires were distributed through an online survey. Only 153 feedbacks will consider analysing the data after the data-cleaning process has been completed. Analysis and discussion will be discussed explicitly in the next phase of this paper.

\section{Data Analysis and Discussion}

The overview and data collection method will explain in detail in this section. 441 Feedbacks from 153 respondents for the online survey in Malaysia were collected and analysed to address the research questions asked at the beginning of this article. Data were seen as far as possible, through diagrams, to recognise and identify any trends that offered the best understanding of the results of the analysis. Details of the survey instrument used 10 questions from the SUS system discussed in the previous section. The questions used in this survey are as in the

TABLE 1 below:

Table 1: Items Used in Survey

\begin{tabular}{cl}
\hline No & \\
\hline 1 & I think that I would like to use this system frequently (positive) \\
2 & I found the system unnecessarily complex (negative) \\
3 & I thought the system was easy to use (positive) \\
4 & I think that I would need the support of a technical person to be able to use this \\
5 & system (negative) \\
6 & $\begin{array}{l}\text { I found the various functions in this system were well integrated (positive) } \\
7\end{array}$ \\
$\begin{array}{l}\text { I would imagine that most people would learn to use this system very quickly } \\
8\end{array}$ & $\begin{array}{l}\text { I found the system very cumbersome to use (negative) } \\
9\end{array}$ \\
$\begin{array}{l}\text { I felt very confident using the system (positive) } \\
\text { (negative) }\end{array}$
\end{tabular}

Source: SYSTEM USABILITY SCALE (SUS) 


\section{Respondents Demographic}

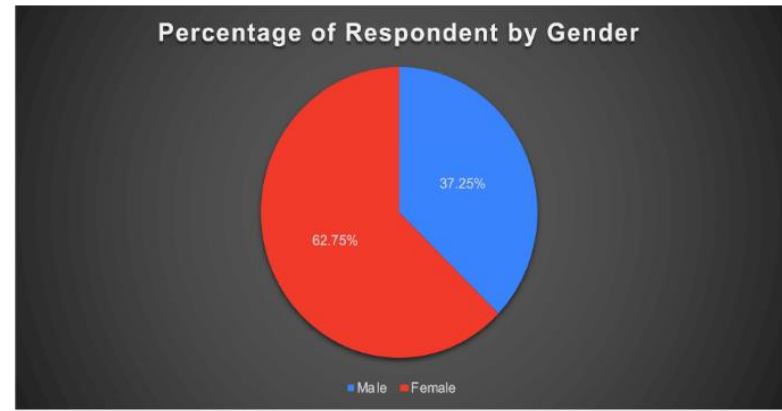

(a)

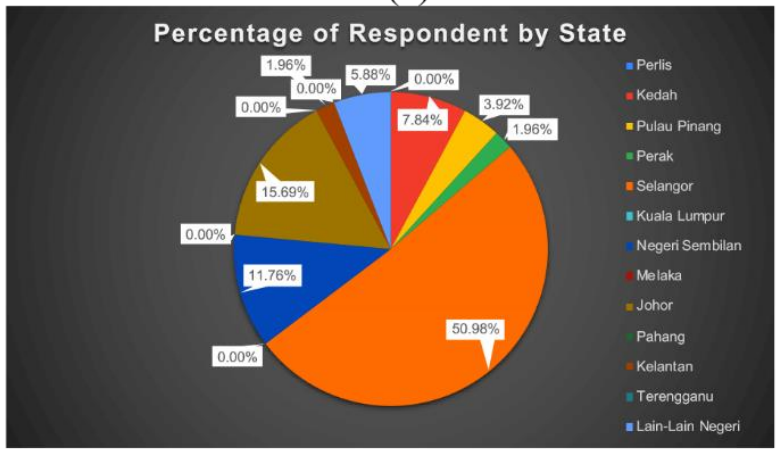

(c)

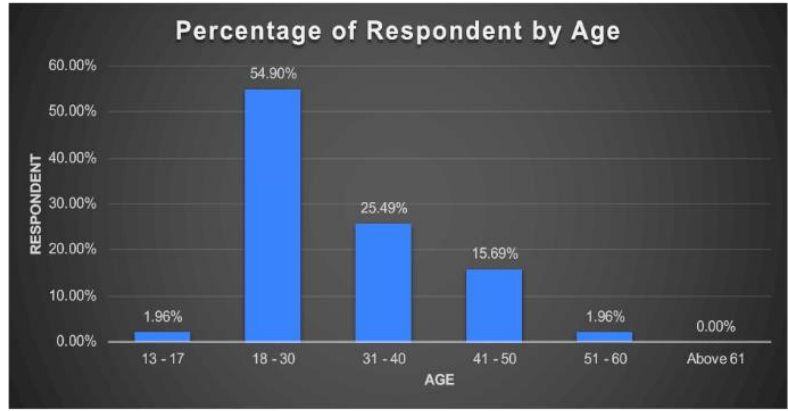

(b)

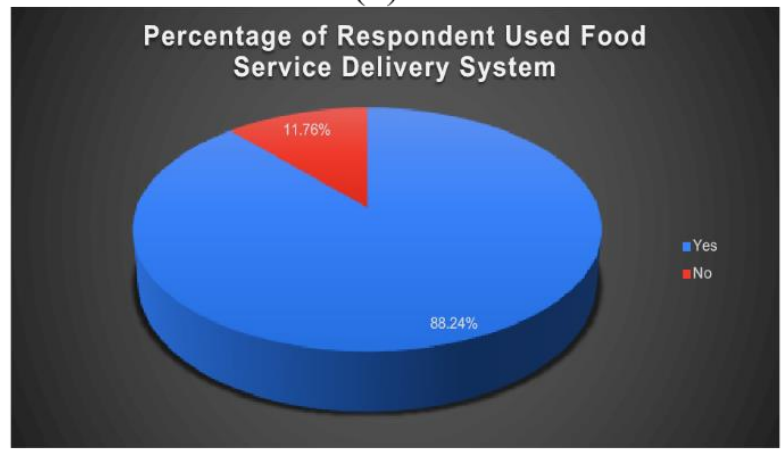

(d)

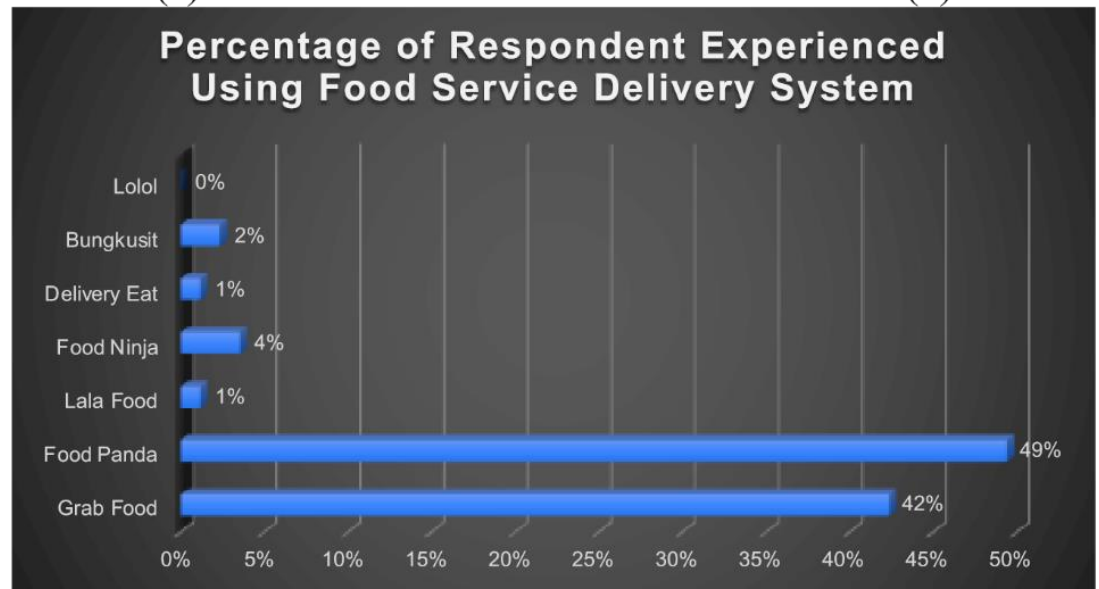

(e)

Figure 1: Demographic and Profile

The distribution of respondents according to gender, age, location, respondents experienced using any food delivery services and also experienced using specific food delivery service system (FIGURE 1). It could be seen that females are $62.75 \%$ and $37.25 \%$ are male. Most of the respondents are with the age group of 18-30 years old. Out of 153 respondents, $50.98 \%$ of them positioned in Selangor, 88.24\% of the respondents have and experienced on using food delivery service system. Most of them are using Food Panda 49\% and Grab Food $42 \%$ for their home food delivery service.

\section{SUS Survey Responses}

Copyright $\odot$ GLOBAL ACADEMIC EXCELLENCE (M) SDN BHD - All rights reserved 


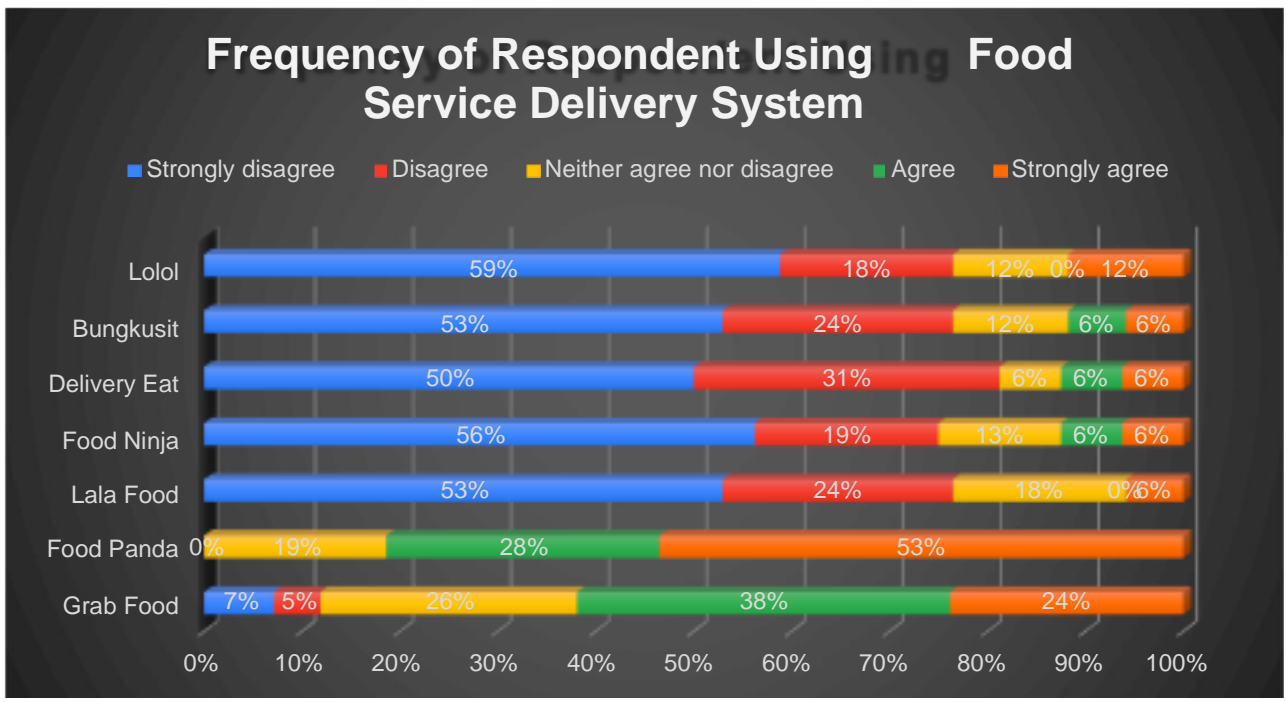

Figure 2: Frequency of Using Systems

From Likert 1-5 scale reactions in FIGURE 2, Grab Food and Food Panda is mainly used by customers to order foods that 53\% of them are using Food Panda and 24\% are using Grab Food.

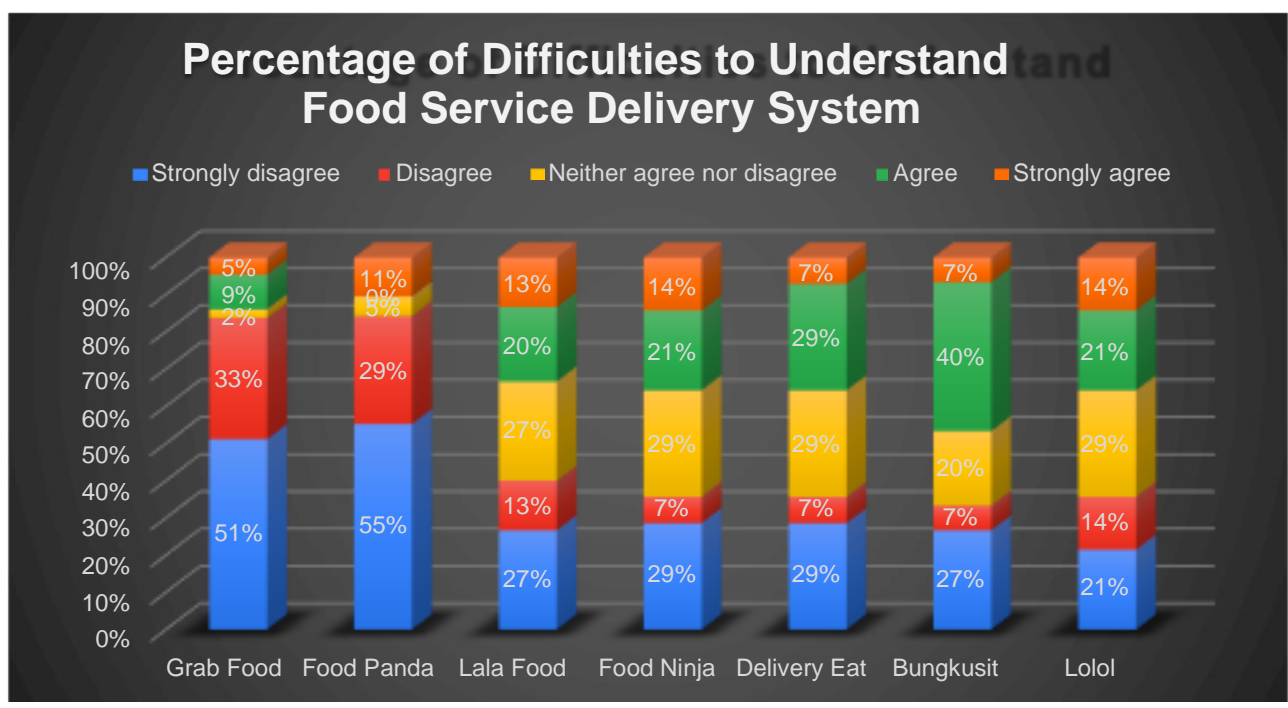

Figure 3: Percentage of Difficulties to Understand

FIGURE 3 shows 55\% of the responses strongly disagree with Food Panda overall system features that it was not easy to understand followed by Grab Food by $51 \%$ responses strongly disagree with the statement. 


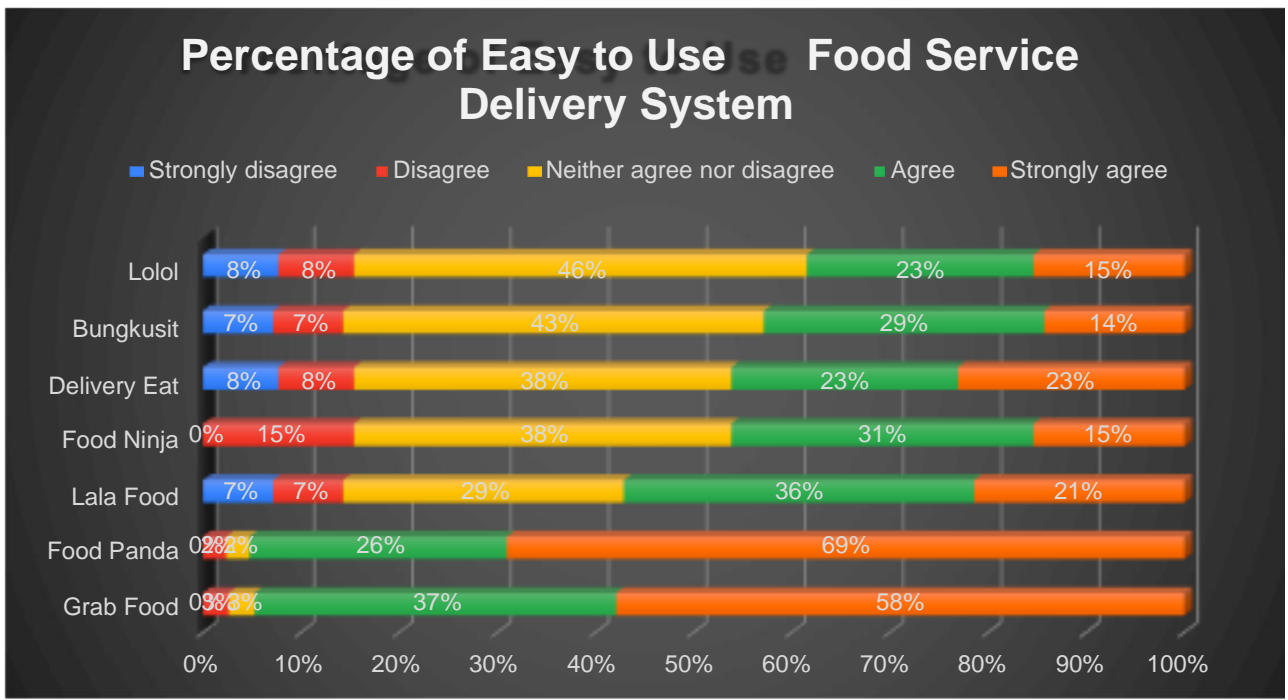

Figure 4: Percentage of Ease Of Use

Out of 441 responses in FIGURE 4, most of them are choosing Food Panda with $69 \%$ and 58\% are choosing Grab Food. Most of the respondents are strongly agree with the statement that these two systems are easy to use for ordering foods.

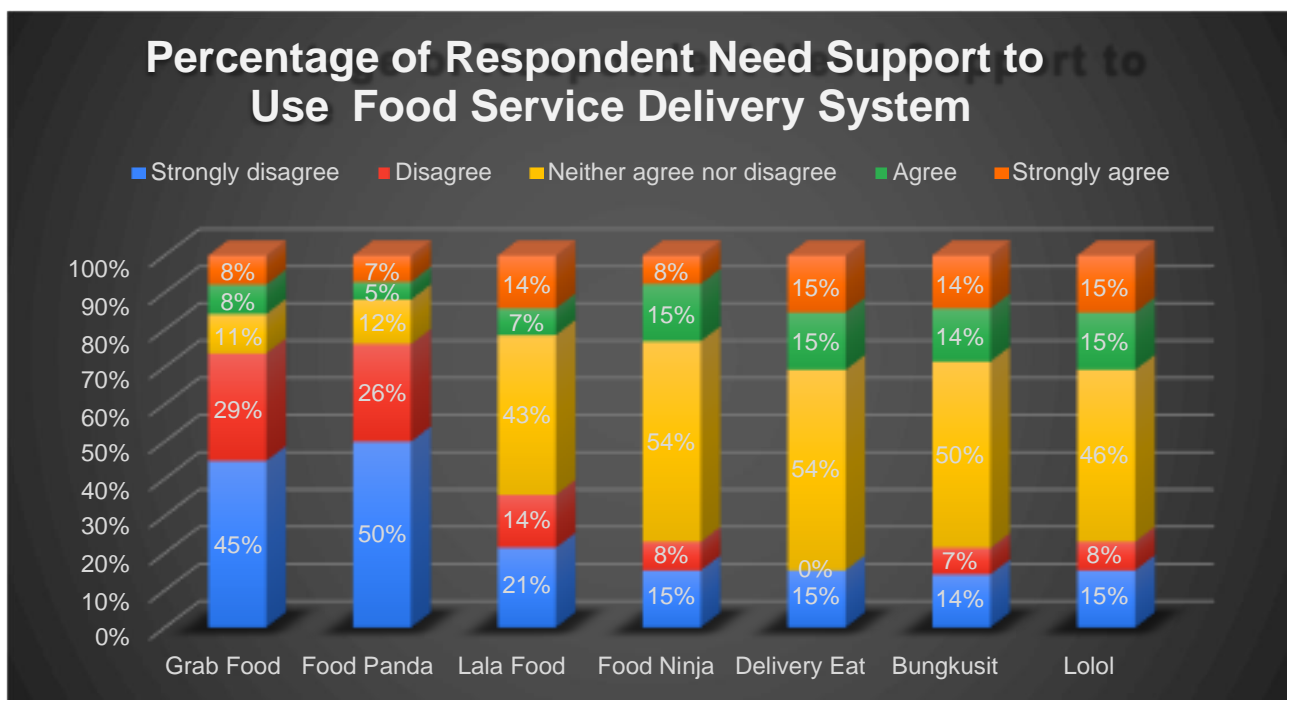

Figure 5: Percentage of Need Support to Use The System

FIGURE 5 showing the results of respondents who strongly disagree on the statement that they need technical support to be able to use the systems. 50\% of users of Food Panda and $45 \%$ users of Grab Food are dominating in this question. 


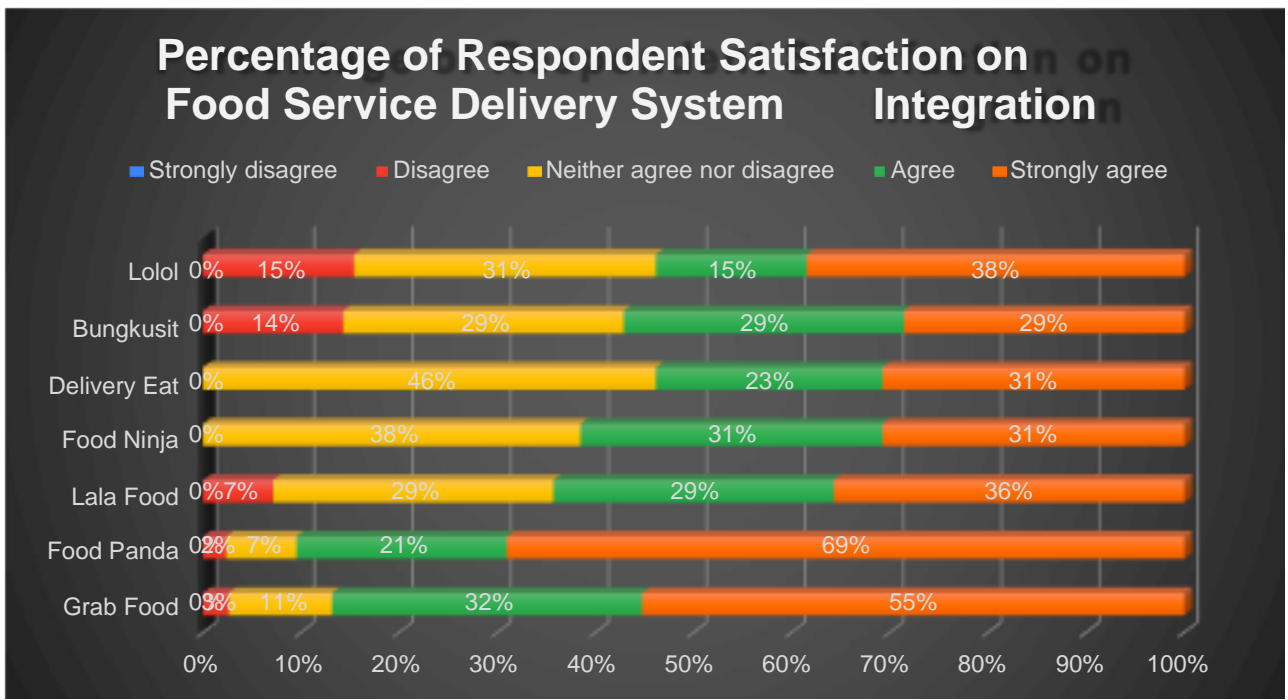

Figure 6: Percentage of Satisfaction on Integration

From the responses obtained 441 responses, 69\% in FIGURE 6 prefer to use Food Panda because of their good integration between all modules and features such as ordering, payment and delivery modules. 55\% are choosing Grab Food followed by Lolol (38\%), Lala Food (36\%), Delivery Eat and Food Ninja (31\%) and Bungkusit (29\%).

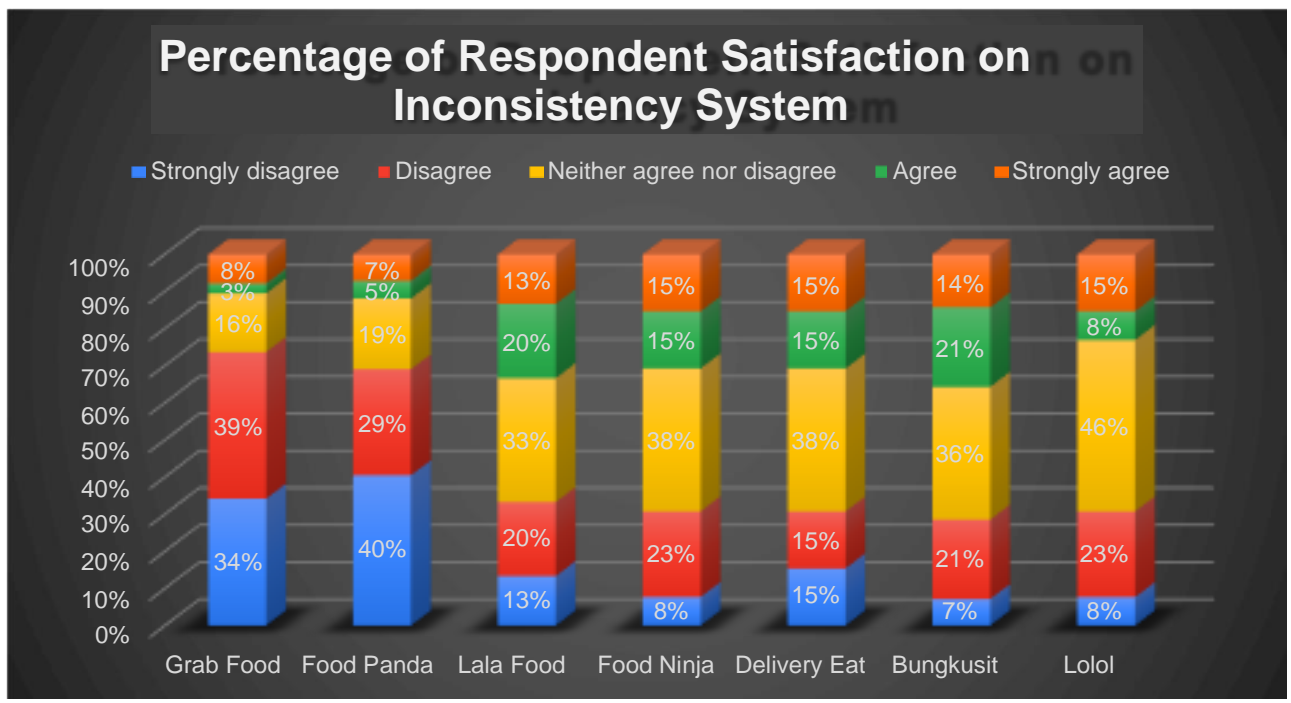

Figure 7: Percentage of Inconsistency System

FIGURE 7 shows $40 \%$ of the responses are strongly disagree with Food Panda inconsistency system features followed by Grab Food with 34\% responses strongly disagree with the statement. Other systems responses are neither agreed nor disagree with this statement which stated Lala Food (33\%), Food Ninja and Delivery Eat (38\%), Bungkusit (36\%) and Lolol $(46 \%)$. 


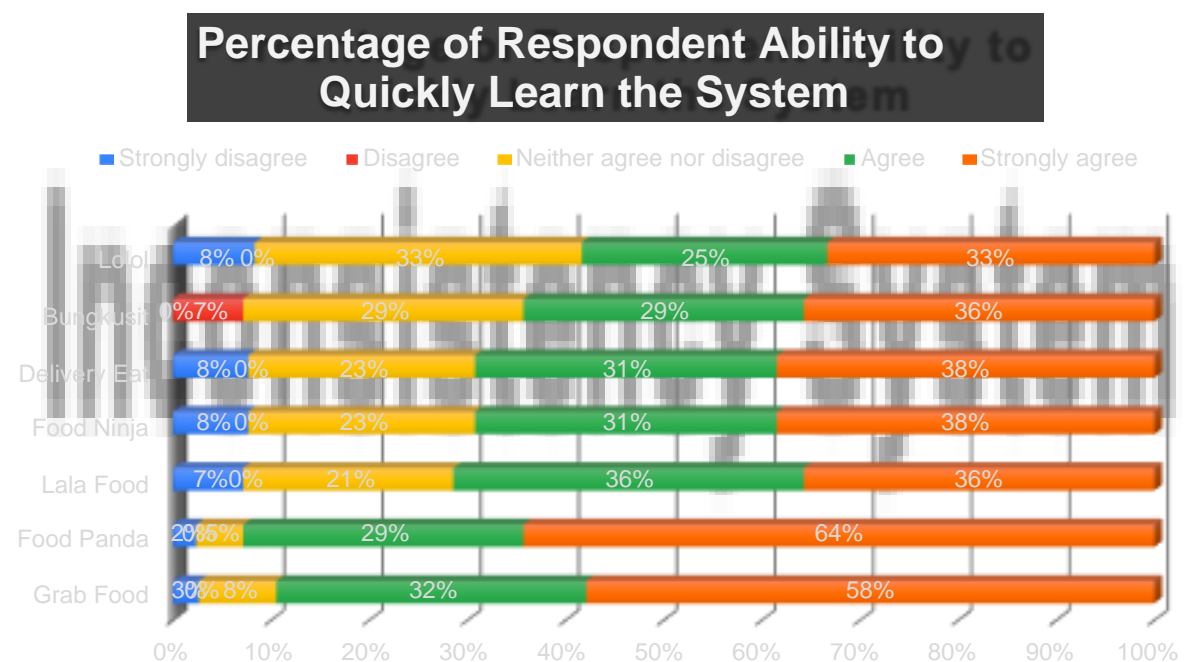

Figure 8: Percentage of Quickly Learn to Use the System

FIGURE 8 showing the results of responses who strongly agree on the statement that they can learn very quickly without any help from technical to use the system. This result in line with FIGURE 4 where the system is very easy to use. 64\% of users of Food Panda and 58\% users of Grab Food are dominating in this question.

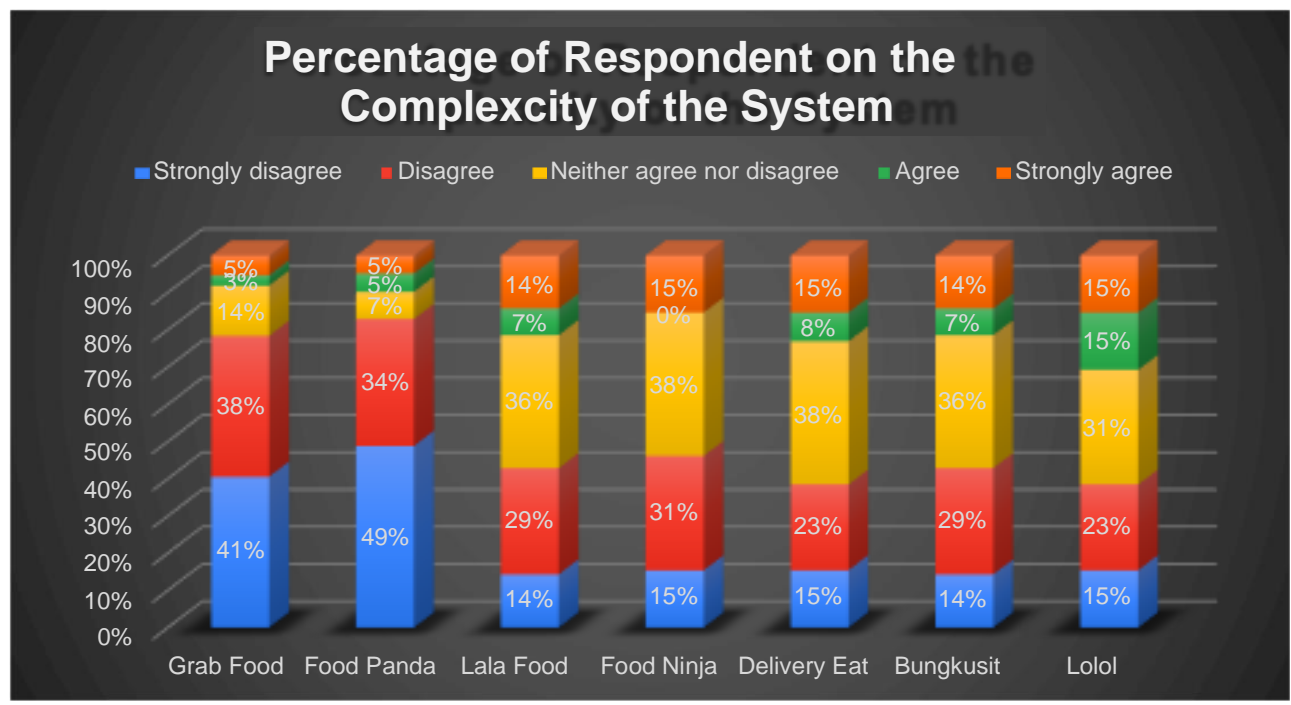

Figure 9: Percentage of System Complexity

FIGURE 9 shows $49 \%$ of the responses are strongly disagree with the complexity of Food Panda overall system followed by Grab Food with $41 \%$ responses strongly disagree with the statement. 


\section{Percentage of Confident to Use the System stem}

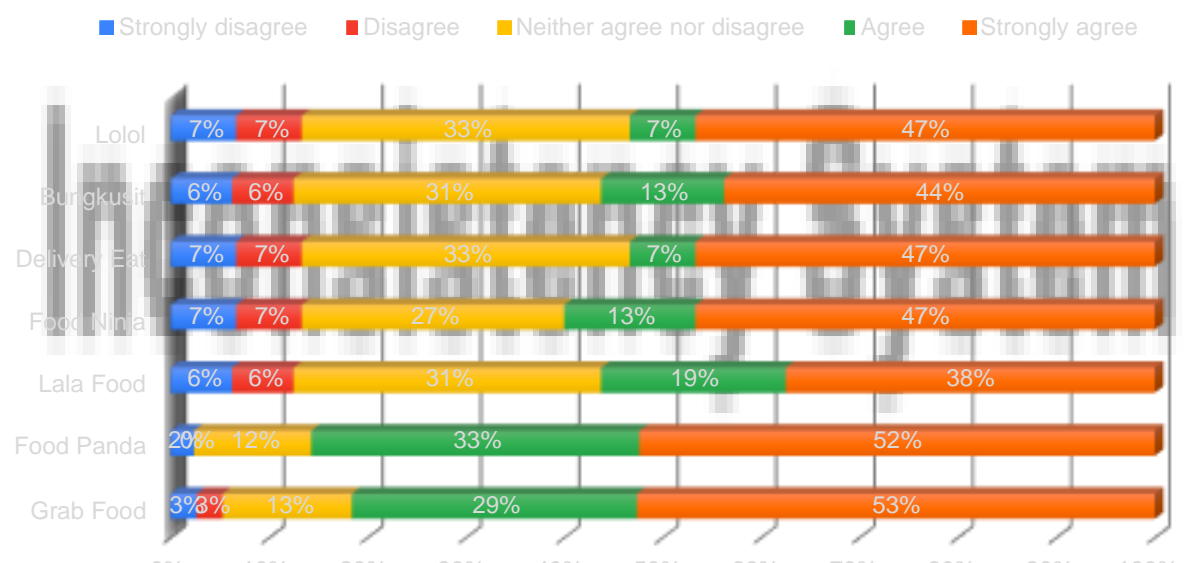

Figure 10: Percentage of Confident to Use System

From the Likert scale responses in FIGURE 10, users of Grab Food and Food Panda were mostly confident to use the systems to order foods which $53 \%$ of them are using Grab Food and 52\% are using Food Panda.

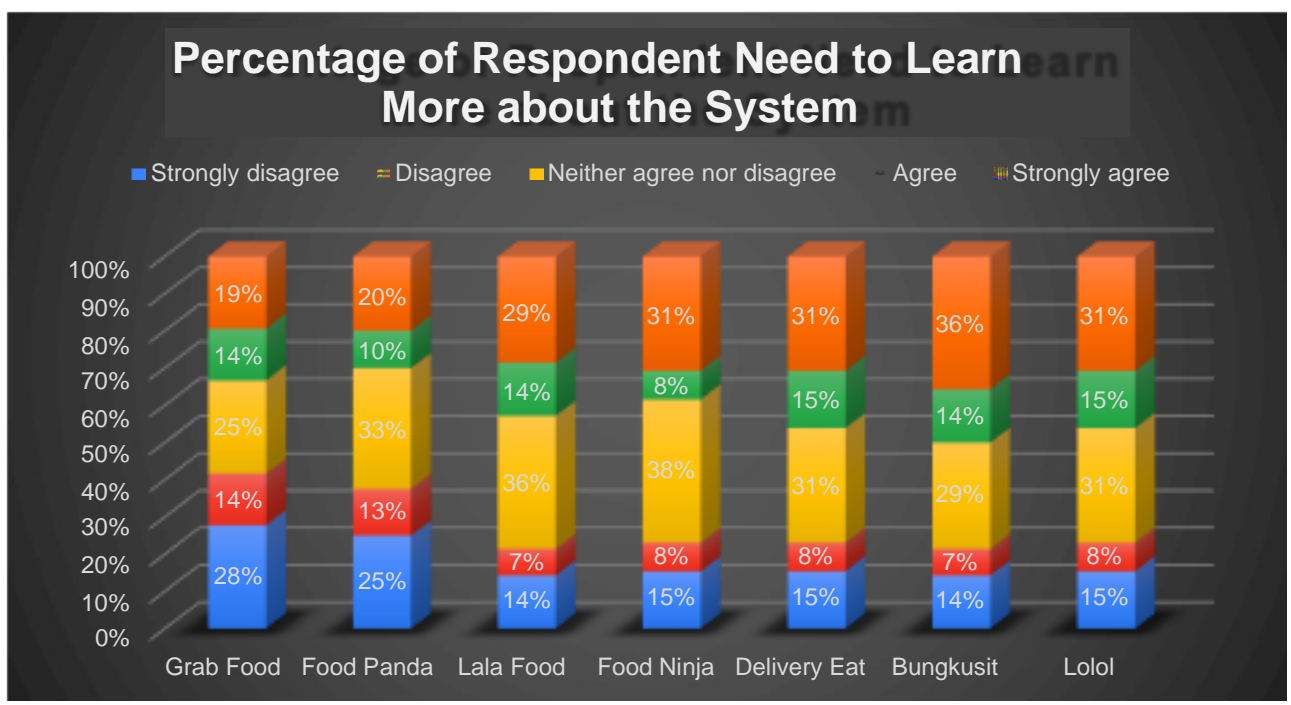

Figure 11: Percentage of Need to Learn More Before Using the System

Out of 441 responses, most of them are choosing neither agree nor disagree for all the systems. The results in FIGURE 11 shown Grab Food (25\%), Food Panda (33\%), Lala Food (36\%), Food Ninja (38\%), Delivery Eat (31\%), Bungkusit (29\%) and Lolol (31\%). In these criteria, most of the respondents are not sure that they need to learn more about the system before they can use the system for ordering foods. 
SUS Score

Table 2: SUS Score

\begin{tabular}{ccccccc}
\hline $\begin{array}{c}\text { Grab } \\
\text { Food }\end{array}$ & $\begin{array}{c}\text { Food } \\
\text { Panda }\end{array}$ & Lala Food & $\begin{array}{c}\text { Food } \\
\text { Ninja }\end{array}$ & $\begin{array}{c}\text { Delivery } \\
\text { Eat }\end{array}$ & Bungkusit & Lolol \\
\hline 70.15 & 75.34 & 51.91 & 51.91 & 51.62 & 51.37 & 51.18 \\
\hline
\end{tabular}

SUS is a very common indicator of perceived usability. It is a 10-item questionnaire graded on a 100-point scale that offers a test of the user's understanding of the usability of the system. For each odd-numbered question, deduct 1 from the score $(x-1)$ and for each even-numbered question, subtract the score from $5(5-\mathrm{x})$. Then sum all scores and multiply the number by 2.5 .

According to Aaron et al. (2008), SUS is only about well above average or well below average which average is the value of 68. Acceptable corresponds to roughly above 70 (above average of 68) and unacceptable to below 50. They designated the range between 50-70 as marginally acceptable.

From the TABLE 2, it shows that Food Panda and Grab Food are accepted by most of the customers to use their systems for ordering the foods and for the other systems such as Lala Food, Food Ninja, Delivery Eat, Bungkusit and Lolol scores are only marginally accepted by the customers.

Mean

Table 3: Mean for Each Items

\begin{tabular}{llllllll}
\hline Questions & $\begin{array}{l}\text { Grab } \\
\text { Food }\end{array}$ & $\begin{array}{l}\text { Food } \\
\text { Panda }\end{array}$ & $\begin{array}{l}\text { Lala } \\
\text { Food }\end{array}$ & $\begin{array}{l}\text { Food } \\
\text { Ninja }\end{array}$ & $\begin{array}{l}\text { Delivery } \\
\text { Eat }\end{array}$ & Bungkusit & Lolol \\
\hline Item 1 & 4 & 4 & 2 & 2 & 2 & 2 & 2 \\
Item 2 & 4 & 4 & 3 & 3 & 3 & 3 & 3 \\
Item 3 & 5 & 5 & 4 & 3 & 3 & 3 & 3 \\
Item 4 & 4 & 4 & 3 & 3 & 3 & 3 & 3 \\
Item 5 & 4 & 5 & 4 & 4 & 4 & 4 & 4 \\
Item 6 & 4 & 4 & 3 & 3 & 3 & 3 & 3 \\
Item 7 & 4 & 5 & 4 & 4 & 4 & 4 & 4 \\
Item 8 & 4 & 4 & 3 & 3 & 3 & 3 & 3 \\
Item 9 & 4 & 4 & 4 & 4 & 4 & 4 & 4 \\
Item 10 & 3 & 3 & 3 & 3 & 3 & 3 & 3 \\
\hline
\end{tabular}

The mean, also referred to by statisticians as the average, is the most common statistic used to measure the centre of a numerical data set. The mean is the sum of all the values in the data set divided by the number of values in the data set. TABLE 3 created from tabular raw data and group it into questions/item and all listed systems. The mean results show all Food Panda and Grab Food customers are satisfied and accept the systems while other systems were neutral from the users toward the systems provided by Lala Food, Food Ninja, Delivery Eat, Bungkusit and Lolol. 


\section{Conclusion}

Result of this research discovering two major and well-known food delivery services systems are regularly used by customers for ordering and delivering their foods. Food Panda and Grab Food are mostly used by the customers in Malaysia while other systems did not receive high demand to use the system. From this research, Food Panda has controlled a major market share although Grab Food has worked together with the state government of Selangor to market their service to the people.

\section{References}

Aaron Bangor, Philip T. Kortum \& James T. Miller (2008) An Empirical Evaluation of the System Usability Scale, International Journal of Human-Computer Interaction, 24:6, 574 594, DOI: 10.1080/10447310802205776

Brooke, J. (1996). SUS: A 'quick and dirty' usability scale. In P. Jordan, B. Thomas, \& B. Weerdmeester (Eds.), Usability Evaluation in Industry (pp. 189-194). London, UK: Taylor \& Francis.

Brooke, J. (2013). SUS: A retrospective. Journal of Usability Studies, 8(2), 29-40.

Chen, M. C., Chang, K. C., Hsu, C. L. \& Yang, I. C. (2011). Understanding the relationship between service convenience and customer satisfaction in home delivery by Kano model. Asia Pacific Journal of Marketing and Logistics, 23(3).

Ghadiyali, N.P.M.S. (2017). A Study on Customer's Attitude and Perception towards Digital Food App Services. Amity Journal of Management, 38.

Gupta, M. (2019). A Study on Impact of Online Food delivery app on Restaurant Business special reference to zomato and swiggy. International Journal of Research and Analytical Reviews, 6(1), 889-893

Ha \& Jang, S. S. (2010). Effects of service quality and food quality: The moderating role of atmospherics in an ethnic restaurant segment. International Journal of Hospitality Management, 29(3), 520-529.

Jacob, A. M., Sreedharan, N. V. \& Sreena, K. (2019). Consumer perception of online food delivery apps in Kochi. International Journal of Innovative Technology and Exploring Engineering. 8 (7S2), May.

Jayadevan, G.R., Natarajan, Thamaraiselvan \& Chandrasekar, K S. (2019). Digital Food Delivery Apps Revolutionizing Food Products Marketing in India. International Journal of Recent Technology and Engineering. 8. 10.35940/ijrte.B1126.0782S619.

Kwong, G., Soo-Ryue, N., Shiun-Yi, W. \& Lily, C. (2017). Outsourcing to online food delivery services: Perspective of F\&B business owners. The Journal of Internet Banking and Commerce, 22(2), 1-18

Lee, S. W., Sung, H. J. \& Jeon, H. M. (2019). Determinants of continuous intention on food delivery apps: Extending UTAUT2 with Information Quality. Sustainability, 11(11), 3141 .

Nicolaides, A. (2008). Service Quality, Empowerment and Ethics in The South African Hospitality and Tourism Industry and The Road Ahead Using ISO9000/1. Unpublished PhD theses, University of Zululand, KwaZulu-Natal.

Okumus, B. \& Bilgihan, A. (2014). Proposing a model to test smartphone users' intention to use smart applications when ordering food in restaurants. Journal of Hospitality and Tourism Technology.2014, 74.

Ray, A., Dhir, A., Bala, P. K. \& Kaur, P. (2019). Why do people use food delivery apps (FDA)? A uses and gratification theory perspective. Journal of Retailing and Consumer Services, 51, 221-230. 
Sauro, J., \& Lewis, J. R. (2009). Correlations among prototypical usability metrics: Evidence for the construct of usability. In Proceedings of CHI 2009 (pp. 1609-1618). Boston, MA: ACM.

Suhartanto, D., Helmi Ali, M., Tan, K. H., Sjahroeddin, F. \& Kusdibyo, L. (2019). Loyalty toward online food delivery service: the role of e-service quality and food quality. Journal of foodservice business research, 22(1), 81-97.

System Usability Scale (SUS). (n.d.). Retrieved 24 November 2020, from https://www.usability.gov/how-to-and-tools/methods/system-usability-scale.html

Van Tonder, C. L. \& Berner, A. (2003). The postmodern consumer: Implications of changing customer expectations for organisation development in service organisations. SA Journal of Industrial Psychology, 29(3), 1-10

Vinaik, A., Goel, R., Sahai, S. \& Garg, V. (2019). The study of interest of consumers in mobile food ordering apps. International Journal of Recent Technology and Engineering, 8(1), 3424- 3429

Yeo, V. C. S., Goh, S. K. \& Rezaei, S. (2017). Consumer experiences, attitude and behavioral intention toward online food delivery (OFD) services. Journal of Retailing and Consumer Services, 35, 150-162

Zviran, M., Glezer, C., \& Avni, I. (2006). User satisfaction from commercial web sites: The effect of design and use. Information Management, 43, 157-178. 